\title{
Incidence of Endodontic Flare-up in Diabetic and Normal Individual: A 100 case study
}

Chowdhury $\mathrm{SS}^{1 *}$, Howlader $\mathrm{MR}^{2}$, karim $\mathrm{AA}^{3}$, Quader $\mathrm{SM}^{4}$

\section{AFFILIATION:}

1. Associate Professor,

Dept. of Conservative Dentistry \& Endodontics, Update Dental College \& Hospital.

2. Associate Professor, Dept. of Conservative Dentistry \& Endodontics Bangabandhu Sheikh Mujib Medical University.

3. Associate Professor,

Dept. of Conservative Dentistry \& Endodontics, Update Dental College\& Hospital.

4. Associate Professor \& Head

Dept. of Conservative Dentistry \& Endodontics, Update Dental College\& Hospital.

\section{Article info.}

Received: 13 January, 2019

Accepted: $15^{\text {th }}$ February, 2019

Volume: 9, Issue-2 October, 2019

DOI: https://doi.org/10.3329/updcj.v9i2.43731

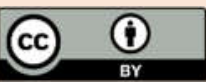

(c) Authors retain copyright and grant the journal right of first publication with the work simultaneously licensed under Creative Commons Attribution License CC - BY 4.0 that allows others to share the work with an acknowledgment of the work's authorship and initial publication in this journal.

https://creativecommons.org/licenses/by/4.0/

Publisher: Update Dental College, Dhaka, Bangladesh

Web: www.updatedentalcollege.edu.bd

E-mail: updcj@hotmail.com

* Corresponding Author

Dr. Shirin Sultana Chowdhury

Associate professor,

Dept. of Conservative Dentistry \& Endodontics, Update Dental College\& Hospital.

E-mail:shumi1177nnn@gmail.com

\section{Citation}

Chowdhury SS, Howlader MR, karim AA, Quader SM, Incidence of Endodontic Flare-up in Diabetic and Normal Individual: A 100 case study. Update Dental College Journal. 2019 October; 9(2): 3-6

DOI: https://doi.org/10.3329/updcj.v9i2.43731

\begin{abstract}
Diabetic mellitus is a burning issue in medical ground. If Pulp or periapical pathology develops on diabetic patient, it may need extra attention to manage by root canal treatment. Because very often diabetic patients develop hyperglycemia, leading complex immune response and enhanced virulence of certain microorganism and commonly cause exaggerbration of inter appointment clinical complain like, pain and swelling known as flare-up. The purpose of this study was to clinically examine the development of endodontic flare-up following endodontic intervention in control and in diabetic patient group. In the present study, overall incidence of inter-appointment flare-up in diabetic patients was found to be $19 \%$ whereas in non-diabetic group, incidence was $8 \%$ that was almost half to the diabetic group. So, this study conclude that root canal treatment can be comfortably done in controlled diabetic patient but need extra care during endodontic treatment if the patient is suffered from uncontrolled diabetes mellitus.
\end{abstract}

\section{KEY WORDS:}

Inter appointment flare-up, Diabetes mellitus, Peri apical pathology, Endodontic treatment.

\section{INTRODUCTION}

An ongoing and frequently vexing problem in endodontics is the development of pain and swelling ("flare-up") during or after endodontic therapy. There are many interrelated hypotheses regarding the pathology which can be summarized as : (a) alteration of the local adaptation syndrome; (b) changes in periapical tissue pressure; (c) microbial factors; (d) effects of chemical mediators; (e) changes in cyclic nucleotides; (f) immunological phenomena; and $(\mathrm{g})$ various psychological factors. Typically, patient with diabetes mellitus are prone to develop infections with a significant defects in immunity, an increased adherence of microorganisms to diabetic cells and presence of micro \& macro angiopathy or neuropathy ${ }^{1}$. During the root canal instrumentation, an acute inflammatory response is initiated in the peri apical tissues that provoke various chemical mediators to release endogenously. At the late stage of acute inflammation, activated complement system which alters cell membranes that increase vascular permeability, chemotaxis of polymorphs and enhance.$^{2}$ This poly morphonuclear leukocyte infiltration may elicit severe reactions due to release of lysosomal contents (lysozyme, collagenases, cathepsins, glucuronidase, peroxidase, amylases, lipases, ribonucleases, deoxyribonucleases, and lactic dehydrogenases) that ultimately causes flare-up in healthy individual. But significantly lower chemotaxis has been noticed in PMNLs in diabetes than contro group.Release of these hydrolytic enzymes produce damage to nearby cells and other tissue elements which ultimately results severe pain and 
swelling causing extensive flare-up. ${ }^{3,4}$

Endodontic infections that are caused by microbial factors are very prevalent and similar to those causing periodontal disease

1. Very often diabetic patients develop hyperglycemia, which can enhance the virulence of certain microorganism, such as Candida albicans. In a hyperglycemic environment, the expression of the receptor-like protein (complement factor $b-$ C3b) of Candida albicans is increased, which results in competitive binding and inhibition of the complementmediated phagocytosis. Significantly lower chemotaxis has been noticed in polymorphoneuclear-leukocytes (PMNs) of diabetic pateints than those of controls.

Since most $\mathrm{PMN}_{\mathrm{S}}$ functions are energy- dependent processes, glucose needs insulin to enter the $\mathrm{PMN}_{\mathrm{s}}$ to generate this energy, which may explain the improvement of the chemotactic response in diabetes mellitus patients. ${ }^{5}$

In diabetic patients, the initial periradicular lesion may increase in size, even with proper endodontic treatment. ${ }^{6}$ Therefore, diabetics patients show higher rate of flare-ups with much lower percent of success rate compared to non-diabetics. These findings strongly suggest that diabetic patients are more prone to be affected by problems of endodontic origin. ${ }^{7}$

Virtually the concepts of doing complete endodontic treatment by a non-surgical approach in the management of periradicular pathosis are not new ${ }^{8-10}$. But diabetic patient have a complex and altered immune functions. Moreover the information available on the pathogenesis, progression and healing of pulpal and periradicular pathosis in dibetic patient is yet unclear. Since the number of diabetic patient is increasing day by day, it has become and an important issue to assess the flare-up presentation in those patient group for better management. Teeth having periradicular pathosis were managed by either extraction or by surgical intervention (e.g. apisectomy) earlier. However, recent development of endodontic procedures (e.g. root canal therapy) indicates nonsurgical approach to treat these conditions. Since the inter appointment flare-up and post-operative complications are common in diabetic patients, endodontic procedure were not usually practiced. However, in this study we found that, if glycemic status of diabetic patients is well controlled and all steps of sterilization procedure is well maintained, conventional root canal therapy will be successful as those of non-diabetic patients even without traditional surgical intervention. Root canal treatment is the preferred management modality for root canal infections ${ }^{5}$ as it is simple, predictable with less complications and time saving.

The purpose of this study was to clinically examine the development of endodontic flare-up following endodontic intervention in control and in diabetic patient group. Such a study seemed indicated in order to further improvement of the current understanding of the longitudinal interrelationship between periradicular pathosis and metabolic control of diabetes mellitus.

\section{MATERIALS AND METHODS:}

A total of 100 cases of endodontically involved non-vital teeth with periradicular pathosis were examined. This was a case control study and the sampling was of purposive sampling. All case selections were limited to the patients presented with endodontically involved teeth at dental department of BIRDEM and Department of Conservative dentistry and Endodontics, Faculty of Dentistry ,Bangabandhu Sheikh Mujib Medical University, Dhaka during the period of January 2007-January 2009 and treatment was completed by conventional root canal therapy. An attempt has been made to explore the etiological basis, age and sex incidence, clinical assessment, methods of diagnosis, treatment plan, inter appointment flare-ups, post operative complaints, complications and immediate as well as long term clinical and radiological follow up of the cases. This series includes all the cases which were clinically and radiologically diagnosed as endodontically involved non vital teeth with peri radicular pathosis. All the teeth were diagnosed by radiograph in standardized position(Bisecting technique) and the study population was received with a pre-operative fasting blood glucose report. The patients were asked about their occupation ,socio-economic condition, general health status, drugs and past dental history and a detailed clinical and radiological examination were done accordingly and diagnosis were confirmed. All patients were divided into two groups -Diabetic and non-diabetic group. Access cavity were initially prepared with round bar and then endo-access bar and the pulp tissue were extirpated by $\mathrm{H}$ - files with vigorous $\mathrm{NaOCL}$ irrigation. Before preparation of root canals a radiograph was taken to confirm the exact canal length. Root canals were prepared with Stainless steel Headstrome-files by standardized technique. During bio-mechanical preparation of the root canals, irrigation was done with $5.25 \%$ sodium hypochlorite solutions and normal saline. Zinc-oxide eugenol sealer and gutta percha cone was used for obturation of root canals. After completion of the treatment a post-operative radiograph also taken to confirm about the quality of the obturation along with fasting blood glucose report.

Long term post operative follow up in all cases of both groups were done at 3 months, 6 months, one year intervals by clinical and radiological evaluation along with blood glucose level. Assessment of inter appointment flare up also done for both group by clinical evaluation. Prophylactic antibiotic was not been advised to any case except those cases were the systemic signs like fever, extra or intra oral swelling were evident.

\section{RESULT:}

Diabetic group showed more flare-up presentation after endodontic intervention than the non-diabetes group (Figure1).Percentage of symptomatic apical periodontitis and periradicular pathosis was more in diabetic group than the control group (Figure-2).Pre-operative complains were more in diabetic group(Figure-3).Time requiring to reduce the size of Periapical radiolucency was more in diabetic than the non-diabetic 


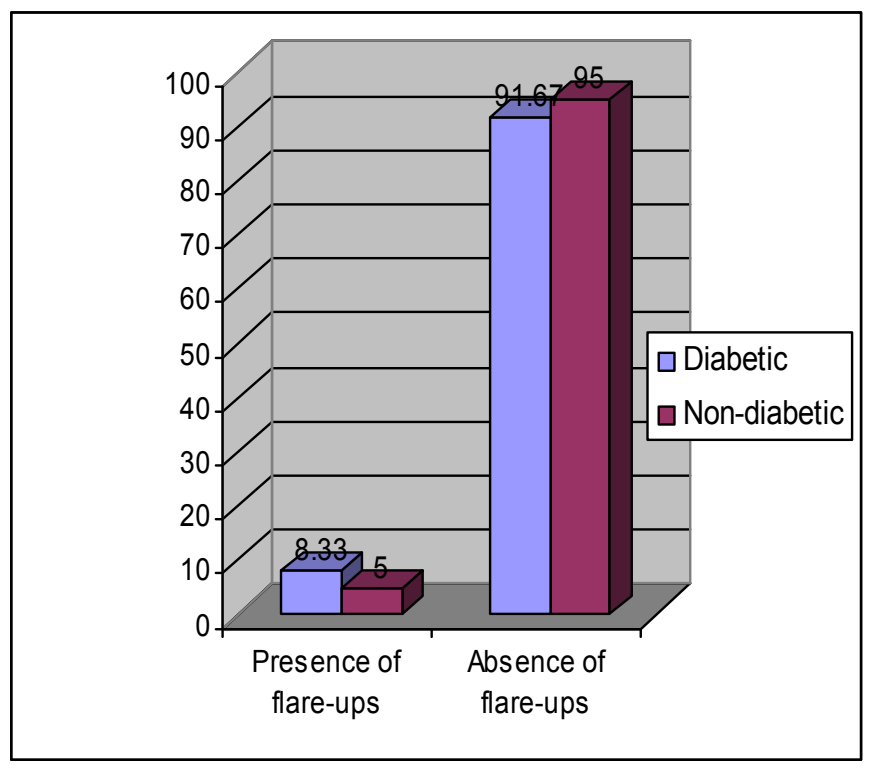

Figure 1: The incidence of flare-ups in all cases from the two patient groups.

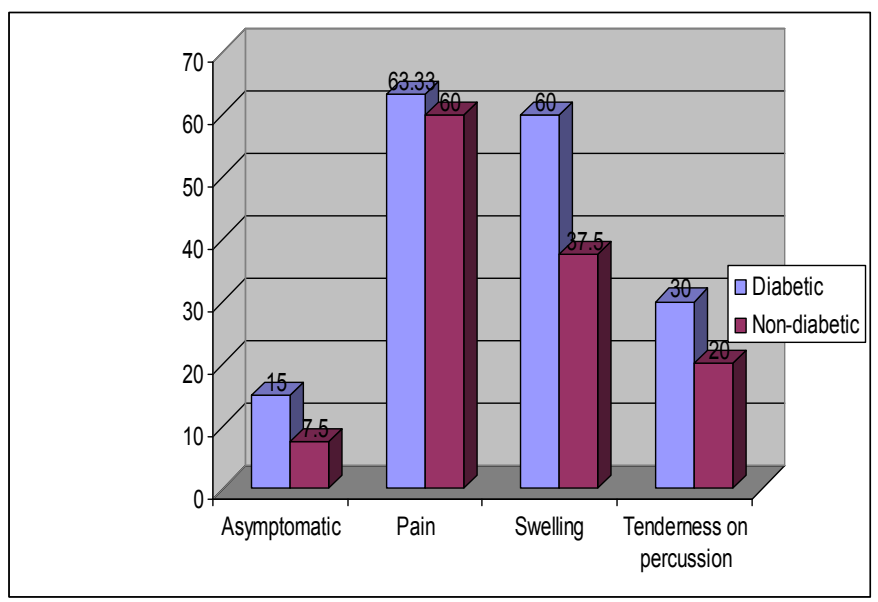

Figure-2: Pre-operative findings of the study objects

\begin{tabular}{lcc}
\hline Flare up & \multicolumn{2}{l}{ Pre-operative pain } \\
\hline & Diabetic & Non-diabetic \\
\hline Present & $19 \%$ & $8 \%$ \\
\hline Absent & $11 \%$ & $37 \%$ \\
\hline
\end{tabular}

Table 1: The relationship of flare up in diabetic group and preoperative pain

\section{DISCUSSION:}

Pain is inherently subjective and its measurements primarily rely on the verbal report of the patients. Several scales and methods have been used for the assessment of pain after endodontic therapy. Among them, the VRS is considered to be a valid and reliable scale for the measurement of pain. ${ }^{1}$ Therefore, VRS was used in this study to evaluate interappointment flare-up. The scores of VRS were categorized into six groups (ranging from 0 to 5) based on the need and quantity of analgesic intake for any pain relief. This was done to make the patient understand the pain scale better and make it clinically more relevant. ${ }^{2}$

A flare-up is said to be those incidences of either severe pain or swelling in $48 \mathrm{~h}$ ( 2 days) after the initiation of the endodontic procedure without any correlation with the number of visits of endodontic treatment. Furthermore, inflammation is said to take at least 10-14 days to subside. ${ }^{1}$ Therefore, the incidence of inter-appointment flare-up in the present study was evaluated on days 1, 2, 3, 7, and 14 .

In the present study, overall incidence of inter-appointment flare-up in diabetic patients was found to be $19 \%$ whereas in non-diabetic group, incidence was $8 \%$ that was almost half to the diabetic group. . A retrospective study that evaluated the effect of diabetes mellitus on the endodontic treatment outcome, using data from an electronic patient record, showed an incidence of flare-up of 4.8 and $2.3 \%$ in diabetic and non-diabetic patients, respectively. Though it was not statistically significant, it was said that diabetic patients had twice as many flare-ups than non diabetic patients. ${ }^{7}$ The increased incidence of flare-up in diabetic patients could be a result of the alterations in immune functions, such as depressed leukocyte adherence, chemotaxis, and phagocytosis, or the presence of more virulent microorganisms in root canals with necrotic pulp of such patients as shown by various studies. ${ }^{4,5,6} \mathrm{~A}$ study by Fouad et al., showed a positive association between the presence of diabetes and certain virulent root canal bacteria. 7,8

DM affects many functions of the immune system and is associated with delayed healing and compromised immune responses. DM-induced changes in immune cell function produce an inflammatory immune cell phenotype (upregulation of pro-inflammatory cytokines from monocytes / poly morpho nuclear leukocytes and down regulation of growth factors from macrophages). This predisposes to chronic inflammation, progressive tissue breakdown, and diminished tissue repair capacity . 9,10

Evidence has consistently indicated that diabetes is a risk factor for increased severity of gingivitis and Periodontitis. ${ }^{11}$ So, it is plausible to hypothesize that DM predisposes to oral infection and could also act as a risk factor for AP, which may expressed as flare up, increasing the rate of root canal 
treatment failure. Several studies have tried to answer this hypothesis. Fouad \&Burleson ${ }^{7}$ investigated endodontic diagnostic and treatment outcome data in patients with and without diabetes.Moreover, several studies have analyzed the possible association between AP and DM, a clinically and genetically heterogeneous group of disorders affecting the metabolism of carbohydrates, lipids and proteins, in which hyperglycemia is a main feature.

Genet et al. found that subject with pre-operative pain had more percentage of flare up than those without preoperative pain which is consistent with the present study. Torabinejad et al. noted that pre-operative pain is a prognostic factor for flare up . ${ }^{10}$ Symptomatic teeth have higher concentration of molecular mediators of inflammation. These mediator decrease firing threshold of pain so that previously nonnoxious or noxious stimuli (e.g. introducing endodontic instruments, irrigates or materials) could be perceived painful or more painful . Walton et al. found that teeth with necrotic pulp are more prone to endodontic flare ups. ${ }^{9}$ Torabinejad et al. also considered that endodontic inter appointment emergency was strongly related to pulp status as a predisposing factor.$^{10,11}$ In our study, pulp status had a substantial effect on prevalence of flare up. The flare up incidence seems higher significantly in symptomatic teeth treated by endodontists. Recent studies also have supported this and showed that incidence of flare up in diabetic patient is more than non diabetic patient especially if the tooth is symptomatic.

\section{REFRENCES:}

1.Lund I, Lundeberg T, Sandberg L, Budh CN, Kowalski J, Svensson E. Lack of interchangeability between visual analogue and verbal rating pain scales: $\mathrm{A}$ cross sectional description of pain etiology groups. BMC Med Res Methodol 2005;5:31.https://doi.org/10.1186/1471-2288-5-31

PMid:16202149 PMCid:PMC1274324

2.Delamaire M, Maugendre D, Moreno M, Le Goff MC, Allannic H, Genetet B. Impaired leucocyte functions in diabetic patients. Diabet Med 1997;14:29-34. https://doi.org/10.1002/(SICI)1096-9136(199701)14:1<29::AID-

\section{DIA300>3.0.CO;2-V}

3.H, Genetet B. Impaired leukocyte functions in diabetic patients.Diabet Med. 1997;14:29-34.

https://doi.org/10.1002/(SICI)1096-9136(199701)14:1<29::AID-

DIA300>3.0.CO;2-V

4. lacopino AM. Periodontitis and diabetes interrelationships: role of inflammation. Ann Periodontol 2001;6:125-37.

https://doi.org/10.1902/annals.2001.6.1.125 PMid:11887455

5. Gomes BP, Sato E, Ferraz CC, Teixeira FB, Zaia AA, Souza-Filho FJ. Evaluation of time required for recontamination of coronally sealed canals medicated with calcium hydroxide and chlorhexidine. Int Endod J 2003;36:604-9. https://doi.org/10.1046/j.1365-2591.2003.00694.x PMid:12950574

6. Genet JM, Hart AA, Wesselink PR, Thoden van Velzen SK. Preoperative and operative factors associated with pain after the first endodontic visit. Int Endod J 1987; 20: 53-64.;134:43-51.

https://doi.org/10.1111/j.1365-2591.1987.tb00590.x PMid:3471726

7.Fouad AF, Burleson J. The effect of diabetes mellitus on endodontic treatment outcome: data from an electronic patient record. J Am Dent Assoc. 2003[12] https://doi.org/10.14219/jada.archive.2003.0016

PMid:12555956

9.Walton R, Fouad A. Endodontic inter appointment flare ups: a prospective study of incidence and related factors. J Endod 1992; 18: 172-177. https://doi.org/10.1016/S0099-2399(06)81413-5
10. Torabinejad M, Cymerman JJ, Frankson M, Lemon RR, Maggio JD, Schilder $\mathrm{H}$. Effectiveness of various medications on postoperative pain following complete instrumentation. Endod 1994; 20: 345-354. https://doi.org/10.1016/S0099-2399(06)80098-1 https://doi.org/10.1016/50099-2399(06)80031-2

11. Salvi GE, Carollo-Bittel B, Lang NP. Effects of diabetes mellitus on periodontal and peri-implant conditions: update on associations and risks. J Clin Periodontol. 2008;35:398-40933.

https://doi.org/10.1111/j.1600-051X.2008.01282.x PMid:18724865 